\title{
PALABRA SOCRÁTICA: UN ENTRECRUZAMIENTO DE PEDAGOGÍA Y PÓLIS
}

\author{
ROBERTO QUIROZ PIZARRO \\ UNIVERSIDAD DE CHILE
}

Resumen: La figura Socrática es un camino filosófico de palabras y de partos intelectuales, un magisterio de la palabra viva. Sin embargo, la palabra misma como material de trabajo queda expuesta a la incomprensión de unos y a la fobia social de una comunidad que aún vive con el miedo a pensar. Doctrina y lenguaje, actitud y finalidad, conforman un drama vivido en la Atenas del siglo $\mathrm{V}$.

Palabras claves: Filosofía, Sócrates, pedagogía de la palabra, sociedad ateniense.

SOCRATIC WORD: A CROSS-FERTILIZATION OF PEDAGOGY AND POLIS Abstract: The Socratic figure is a philosophical path of words and intellectual births, a magisterium of the living word. However, the word itself as work material is exposed to the misunderstanding of some and the social phobia of a community that still lives with the fear of thinking. Doctrine and language, attitude and purpose, form a drama lived in the Athens of the fifth century.

Keywords: Philosophy, Socrates, pedagogy of the word, Athenian society.

Recibido: 10.06.2016 - Aceptado: 14.07.2016

Correspondencia: Roberto Quiroz Pizarro

Email: alfanamaste@hotmail.com

Lic./Mag. Filosofía - Universidad de Chile. CDoctor Universidad de Chile

-- CDoctor Universitat Jaume I-Valencià 


\section{Retratos de un imposible}

Tada uno tiene en la memoria la imagen de un ateniense cuya peculiaridad callejera era la de hablar con los habitantes de la pólis, la de estar dispuesto a improvisar amenas y curiosas especulaciones en una atmósfera de palabras tal como legendariamente lo fuera un aedo homérico. Es una invitación extraña que no tiene precedentes habituales porque no es la estampa pasada del profeta o la del caudillo político que busca la fuerza ideológica o el sometimiento de las voluntades, nada parecido a un movimiento de masas en nuestra contemporaneidad. Figura atípica y a la vez primordial es la que va y viene con Sócrates, y ante el cual todas las cosas del mundo cotidiano y convencional no parecen estar seguras. Hombre de ciudad, del ágora, invitado a banquetes y una personalidad de ensimismamientos. En una palabra, los escasos antecedentes y las imágenes dadas por los testimonios más cercanos -entre ellos Aristófanes, Platón, Aristóteles, Jenofonte- no concuerdan doctrinariamente pero sin embargo, revelan que hubo un aire y un gesto pedagógico, orientador, especulativo, de cuestionamientos vitales y filosóficos de lo que hoy se diría existenciales. Dentro de lo nebuloso, hay un rostro socrático.

Un hecho nada común de lo que fue la puesta en escena social y la impronta socrática radica en los puntos extremos de por donde cruzó el ejercicio de su palabra: explorar la flexibilidad del logos, la que a veces podía consistir en un juego de lenguaje en el que el hombre hablaba oyendo lo que dice, siendo testigo de su decir, jugando a oír palabras propias y ajenas, pero también oyendo el lenguaje original del que el homo sapiens es el gran curioso, e incluso, yendo lo más lejos en el uso de las palabras, Sócrates es quien nos quiere llevar a aprender a pensar y aprender a dudar. Nada menos que algo evidente y también olvidado en la cotidiana facilidad.

Los autores que tuvieron contacto directo o bien noticias suyas, parecen hablar en una especie de contrastación y lenguaje metafórico: mencionan por un lado, la acentuada fealdad corporal versus la belleza humana de Sócrates; o bien la personalidad de juego y humor que se asentaba en su lenguaje junto al rigor extremo de sus análisis conceptuales -bastaría recordar que hasta en sus últimos momentos de vida, antes de la cicuta por destino, mantuvo un buen ánimo y una moderada ironía en sus palabras a sus amigos; por otro lado, se nos habla de un maestro cercano a sus discípulos pero también de un personaje público y amigo de toda la ciudad; o de un filósofo callejero que decía no saber nada pero que pretendía que todos "comiéramos del fruto prohibido del 
conocimiento", lo que por cierto, es una elocuente declaración de guerra ante el relato bíblico del Génesis. Aún nos queda una imagen difícil de precisar en lenguaje de palabras: quizá todo hombre aún racional y en trance de la muerte, a pocos minutos de verse partir de la vida, estaría bajo colapso del temor y en el quiebre de su mente normal, incapaz de algo más. Además, como una persona de carne y hueso, es llamativa la última escena que tenemos de la presencia de Sócrates. A modo de recuerdo intertextual volvamos al personaje bíblico del Nuevo Testamento en su postrera hora, en donde pudo exclamar en el paroxismo del tormento físico “¡Dios mío, Dios mío!, ¿por qué me has abandonado?”. En las últimas palabras socráticas también hay pregunta en extremo realista, imprevista, y una alusión a los deberes: al mismo centinela que trae la copa envenenada le solicita una opinión, “--dime, amigo, tú que sabes estas cosas, ¿qué debo hacer?”, y minutos después, dirigiéndose a su discípulo, "Critón, le debemos un gallo a Asclepio, ¿te acordarás de pagar ese compromiso?"'.

En fin, deber para con los discípulos, deber para con los ciudadanos de la pólis, deber para con los dioses, deberes todos que partían en Sócrates desde la palabra, el pensamiento, la acción social y la coparticipación política.

\section{Filosofía socrática, un camino peligroso}

Para acercarnos a la senda del Humanismo o para elegir hacernos parte de una cultura humanística no hacen falta instituciones ni actos de fuerza para que el individuo siga a un líder o adhiera a una causa fruto de la predicación. Si de algo y para todo tiempo ha de servir el ejemplo de un tal Sócrates, éste sería mostrarnos que no hay mayor fecundidad que la de seguirse a uno mismo. En el sentido, la historia nos dice que esto del humanismo es un extraño fenómeno que incluso puede acabar mal, trágicamente, tal como lo sucedido en la Atenas del año 399. a.C ${ }^{2}$, cuando un atípico filósofo (melenudo, mal vestido, resistente

1

Platón (2007). Fedón, p. 140-41. Al respecto no hay una opinión consensuada acerca de la referencia a Asclepio, y unos consideran que se trataría de una ironía más propia de Sócrates, otros de un acto de piedad y conciencia religiosa. Otros ven más bien una pincelada literaria de fondo platónico.

2 Funesta fecha en que se llevó a efecto el juicio a Sócrates (469?-399), el filósofo de la Atenas clásica. Testimonio de tan emocionante episodio es la obra que su discípulo Platón nos entrega en la Apología. No hay un acuerdo plenamente taxativo de los analistas sobre lo que sucedió a la sociedad ateniense para que el conflicto resultara en un ajusticiamiento, más cuando se sabe se trató de un filósofo de la palabra que no dejó nada escrito. 
a los brebajes dionisíacos) fue puesto bajo sospecha por toda una ciudad. Allí, en el 399, como antes en las Termópilas, aprendimos una amarga lección: que el espíritu libre no se rinde y que no pierde su dignidad ni ante persas o jueces atenienses perseguidores. En ese año, palabra y política, ciudadanos e intelectuales, se encontraron y se vieron las caras.

A tal punto debió tener la palabra de Sócrates una lectura politizada y desconcertante por parte de la polis que tuvo que ser llevado a un tribunal público, máximo actor social avalado por la institucionalidad. Esto quiere decir que el mensaje socrático profesado de palabras y acciones había dejado una profunda huella como para hacerlo objeto de acusaciones, unas que traían diversos ecos del entorno. Los hechos de las acusaciones también podrían estar insertos en una dimensión jurídica delicada, ambigua y sospechosa de lo que es su enfoque final de probatorio o absolutorio ante los cargos en litigio. Una vez leído el registro literario-filosófico del proceso que nos da Platón, queda la extraña sensación de sí más bien no fue el propio Sócrates quien dirigió los entresijos de su destino. Al respecto surgen al menos unas cuántas conjeturas de observador lejano: por ejemplo, preguntar si más bien Sócrates ¿era ya un personaje sancionado y estigmatizado por el rumor social, por la envidia y antipatía de sus conciudadanos? O lucubrar si acaso ¿fue tan ciega la polis de su tiempo como para sentirse amenazada por la palabra de un solo hombre? ¿Qué hubo en la figura socrática tan disonante, tan vanguardista o quizá tan hereje como para procesarlo en vez de simplemente, expulsarlo de la ciudad? O acaso, ¿fue por la índole de su mensaje (entiéndase contenido, dirección ideológica, oleaje crítico) o fue por la personalidad misma unida a un imperativo filosófico lo que impidió una interpretación aceptable y tranquilizante para las conciencias atenienses?

Ante los ojos de la polis uno se pregunta cómo habrá sido visto un ciudadano tal, ya ligeramente afamado, conocido, no sólo por sus "tropelías dialogantescas" sino también por haber sido expuesto a escena pública en las manos de un genial Aristófanes en el año $423^{3}$. De los testimonios que puedan

En tal año se presentó la célebre obra aristofanesca que puso en escena a un Sócrates tal que pasó a ser la versión controversial del comediante ático. Entre las variadas complejidades que se activan al revisar esta obra de Aristófanes emerge la del problema de datación y versión conservada que tenemos de ella. En efecto, de Las Nubes parte ya el problema de que no tenemos el texto originalmente presentado en las Dionisias del 423, lo cual ha despertado una serie de hipótesis entre los estudiosos. Se sabe que conservamos una versión revisada, la cual probablemente llevo tiempo, varios años de por medio. Quizá 421 o 417, o hasta se propone el 414 (Erbse, Kopff, Storey). 
contarse como cercanos, hay varias imágenes antropológicas en tensión. Una interpretación que ve a un Sócrates hijo de la razón y de la palabra cuestionadora; un Sócrates moralista, humanista, un quijote defensor del deber personal; un Sócrates que toma su vida privada-pública bajo la consigna de una misión délfica y del cuidado del alma. La antítesis de estas visiones tiene perfecta cabida con la figura de quien irradia una tan compleja presencia callejera en la ciudad. En su Paideia, Jaeger comenta que la "anfibología tiene que residir en la personalidad misma de Sócrates que lo hace susceptible de esta doble"4 interpretación --o más diríamos nosotros-- que se atribuyen al controversial personaje.

\section{Palabra encarnada: paideia}

Nuestra tesis ${ }^{5}$ o mirada conductual es acentuar un poco lo que se toma por un detalle menor, secundario, accidental, y subirlo a otro nivel hermenéutico. Entonces decimos que fue el arte de la palabra en escena lo que llevo a los atenienses a tomar una decisión política en contra de Sócrates, tanto o más que las mismas acusaciones judiciales esgrimidas.

Desde tiempo homéricos los griegos fueron vistos como un pueblo elocuente, locuaz, abierto a la palabra en toda su plasticidad creadora, narrativa y agonística. El uso de la palabra misma es una "auto afirmación", un "acto de identidad", una "presencia poiética de sí" en la que todos somos aristotélicamente "retóricos" en el buen y mal sentido, "puesto que, hasta un cierto límite todos se esfuerzan en descubrir y sostener un argumento e, igualmente, en defenderse y acusar"', según señala el estagirita aludido. Cierto que ha pasado el tiempo entre Homero, Aristóteles y nosotros, y que no se ha perdido esta necesidad antropológica de hablar y dialogar, y es más, sabemos que no todos poseemos el mismo registro sonoro de la elocuencia, la oratoria, la retórica, al momento de hacernos oír. Y Homero bien que lo sabía: "Los dioses no han repartido de

También Dover plantea que Aristófanes no acabó su revisión. Lo que se puede asegurar es que hubieron dos versiones, que la primera fue la que se representó y que la segunda es la que se ha conservado.

Jaeger, W., (1945): II, p. 29.

5

La fundamentación y vía de desarrollo es un paralelo a las tesis de G. Vlastos quien ha destacado esa dimensión ironista socrática como eje central de su filosofía. A juicio propio agregamos esta tesis de que hay que indagar una causa endógena y no exógena para comprender los alcances del juicio mismo contra la figura de Sócrates. 
igual modo a todos los hombres sus amables presentes: hermosura, ingenio y elocuencia. Hombre hay que, inferior por su aspecto, recibe de una deidad el adorno de la facundia y ya todos se complacen en mirarlo, cuando los arenga con firme voz y suave modestia, y le contemplan como a un numen si por la ciudad anda [...]"?

Este fenómeno según las fuentes pudo sucederle en sumo grado a ese tal Sócrates, el filósofo parlanchín, pero la coincidencia de este caso no implica que los otros griegos de su tiempo no tuvieran ese mismo talento natural de la palabra. En efecto, "en la Grecia de Atenas el pueblo es gobernado por sus oradores", con lo cual se quería decir que en esta polis todo dependía del pueblo y éste de sus oradores. Platón nos lo dice en Leyes: "todos los griegos suponen de nuestra ciudad que es amante de la palabra y que le agrada hablar mucho $[\ldots]$ ". Se decía y se pensaba esto porque los griegos, sobre todo los atenienses, poseían "una avidez natural por oír a los que hablaban bien. Por eso la sofistica, que hace profesión de deleitar con la palabra, va a ser tan bien acogida. El ciudadano ateniense no tanto oye para ver lo que debe hacer, como por el mismo placer de oír" 9 . Sin embargo, lo que sabemos a posteriori de ese manifiesto placer por el discurso, de esa intelectualidad mayeútica y aún vivaz en el ciudadano de 70 años, es que no encontró suficiente apoyo en la concurrencia del juicio como para dejarlo vivir en la amada Atenas. Sócrates fue sentenciado a la cicuta.

Según se sabe, la "ley ateniense, una vez declarado Sócrates culpable en una primera votación, le concedía el derecho de escoger alguna otra pena alternativa: la prisión redimible con una multa o destierro. Sin embargo, Sócrates, por no aceptar su culpabilidad, tampoco aceptó la alternativa. Más aún, irritó a los jueces con sus ironías, proponiendo que se le condenara a ser alimentado por cuenta de la ciudad”, lo cual era un escándalo racionalmente olímpico. "En último caso" --el acusado-- "se mostraba pronto a pagar la ridicula multa de una mina. El resultado fue que, en la segunda votación, ya no quedaba más sentencia que la pena de muerte, y los votos esta vez fueron más desfavorables. Lo que se pretendía de Sócrates es que se humillara, que pidiera gracia. No quiso doblegarse, porque se sentía inocente" ${ }^{\prime 10}$. Una vez

\footnotetext{
$7 \quad$ Homero (1927): VIII, 166, p. 354.

8 Platón (1999): I, 641e, p. 224.

9 Aristóteles (1951): p. 15.

10 Reyes, A. (1941): p. 106.
} 
encarcelado, sabemos que tampoco quiso aceptar la fuga que le propusieron sus amigos cercanos. Por tanto, se levanta aún más la impresión que Sócrates manejó su destino trágico, no que lo haya negociado.

En esta mínima, secuencial y episódica línea narrativa del juicio llamado Apología, hicimos mención de que la tal "ironía socrática" exasperó y descontroló al cuerpo de los jueces y acusadores. Pero ¿qué es la ironía en cuestión? y a su vez, ¿qué camino tomó la ironía en el gesto pensante de Sócrates?

\section{Un juego filosófico, intelecto e ironía}

"Ironía", dice Quintiliano, es aquella figura de dicción "donde debe entenderse algo contrario de lo que es dicho" (contrarium ei quod dicitur intellegendum est ${ }^{11}$. Esta formulación ha resistido al tiempo. Ha pasado inalterable a muchos diccionarios, y sobrevive casi inalterable hasta nuestros días: hoy "ironía es el uso de las palabras para que expresemos algo, particularmente lo contrario, de su sentido literal".

En este recorrido de lo ya señalado y teniendo a Sócrates como figura fondo, es oportuno preguntarse si acaso ¿es un placer culposo, un juego vital y existencial ${ }^{12}$, esto de usar, mezclar la retórica, la ironía, la ambigüedad discursiva y el sentido lúdico hecho palabra?

Para nosotros se usa la ironía en primer lugar, por ánimo de humor, de jugar con la distensionalidad del lenguaje. Después, por burla. Una vez que comprendemos esto modernamente, podemos volver a los antiguos griegos y descubrir con sorpresa que la intención de engaño, de fingimiento, tan extraña a nuestra concepción moderna de la ironía -en el sentido de hilaridad o humor negro, de burla o menosprecio ácido--, era lo natural en las palabras antiguas relacionadas con ironía; por tanto, ironizar para los primeros griegos era un fraude encubierto, un acto de mala fe discursivo, una trampa en el lenguaje, un evento retórico, una intencionalidad sofística. Se pueden mencionar algunas apariciones en el corpus de los textos áticos que han llegado hasta nosotros.

11 Quintiliano (1914): IX. II. 44. Véase referencias a Sócrates como el gran ironista pp.91-92.

12 Psicólogos e investigadores contemporáneos destacan el valor terapéutico del juego, "es una actividad o proceso antiguo, voluntario, inherentemente placentero y sin propósito aparente, que es un fin en sí mismo, y que refuerza los músculos y las habilidades sociales, nos ayuda a evadirnos y nos proporciona un estado de bienestar", puntualiza, Stwart Brown. 
Aristófanes ${ }^{13}$ en las Avispas 174, muestra como la ironía se refiere a la mentira que utiliza un personaje (Filocleon) para conseguir un fin. En las Aves 1211, se refiere a la diosa lris, la cual utiliza mentiras para entrar en la ciudad de los pájaros. En las Nubes $^{14} 449$, la palabra ironía, entre otras que significan astucia, marrullería, es algo propio de un insulto. Encontramos otros ejemplos en los escritores del siglo IV. Demóstenes ${ }^{15}$ se refiere a la ironía con relación a cierto tipo de ciudadanos simuladores de la verdad a fin de evitar obligaciones políticas. Sócrates, Platón, Aristóteles, van a criticar al irónico como simulador, como pariente del sofista, como un impostor del discurso, como un interlocutor que se aprovecha de la parresía ${ }^{16}$. En el Sofista se da una especie de contrastación entre lo que sería la dialéctica de Sócrates calificada como una forma superior de sofística (321 B) y el demoledor arte irónico propio de la sofística tradicional en manos de los sofistas y abusadores de la palabra. No es contra Sócrates sino a sus antípodas, a sus adversarios extremos --a los que Platón considera como engañadores--, a los que denomina ironistas (268 A).

Este horizonte semántico platónico del acostumbrado ironista como acto de insinceridad lo podemos conectar con el de otros autores como Aristóteles y Teofrasto ${ }^{17}$.

Aristóteles mantiene cierta simpatía, una opinión permisiva, tolerante, con la ironía: "Pues bien, el jactancioso se cree que es el que pretende reputación en cosas que no le pertenecen, mientras que el irónico niega lo que le pertenece o le quita importancia. El término medio, contemplando la situación como es, parece ser un hombre sincero tanto en su vida como en sus palabras [...]

"Los irónicos, que minimizan sus méritos, tienen, evidentemente, un

13 Cavallero, P. (2005): “Trygoidía : la concepción trágica de Nubes de Aristófanes”, XIII Jornadas de Estudios Clásicos “Grecia y Roma en España”, UCA, Argentina, Biblioteca digital. pp- 1-12.

14 Dover, K. (1968): Aristophanes, Oxford, Oxford Univ. Press: pp. V-IX.

15 Demóstenes, Filípica I, vii

16 En la retórica clásica la parresía era una manera de «hablar con franqueza o de excusarse por hablar así». El término está tomado del griego y significa literalmente «decirlo todo»y, por extensión, «hablar libremente», «hablar atrevidamente» o «atrevimiento». Implica no sólo la libertad de expresión sino la obligación de hablar con la verdad para el bien común, incluso frente al peligro individual.

17 En adelante seguimos los lineamientos y sugerencias de G. Vlastos (1991) Socrates, Ironist and Moral Philosopher, Cornell University Press. 
carácter más agradable, pues parecen hablar así no por bueno, sino por evitar la ostentación. Éstos niegan, sobre todo, las cualidades más reputadas, como hacia Sócrates" "18. A lo menos en las palabras de Aristóteles hay un relativo rescate de la figura socrática y, al presentarlo como irónico, lo compara con su contrario, el jactancioso (impostor-charlatán), y lo encuentra positivamente preferible, porque Sócrates siendo irónico no busca la jactancia, y menos actuar bajo una voluntad de engaño malicioso. En Teofrasto, en cambio el irónico (el simulador) es criticado implacablemente, presentado como sistemáticamente engañador, dolosamente de doble cara.

Volviendo a Platón, uno puede recordar el pasaje donde Trasímaco se queja de la actitud de Sócrates (Rep. 337) y lo acusa de su acostumbrada ironía. Lo acusa de que miente o engaña cuando dice que él mismo que no tiene respuestas a las preguntas que plantea a los otros, y seguramente sí que las tiene. Esto hace protestar a Trasímaco, pues dice que Sócrates finge que no las tiene para mantenerlas ocultas, a fin de tener el campo libre para poder atacar las opiniones de los demás y despedazarlas, mientras que las del filósofo ironista por excelencia, están protegidas de cualquier ataque. Sin embargo, a pesar de la queja trasícamaquiana diremos que no convence absolutamente que la ironía en juego se traduzca en estos casos bajo algún sentido burlesco malicioso o de engaño premeditado (Bloom, Grube, Shorey ${ }^{19}$ ). Más valdría traducir la actitud de Sócrates como que "ironiza" y usa de la polifonía irónica antes que charlatanear o embaucar o engañar de mala fe.

Por el comportamiento de la palabra ironía en estos contextos señalados Platón, Aristóteles, Teofrasto, se podría descartar que ella sea socráticamente utilizada para manifestar insidiosa o premeditadamente un discurso sofismático o una conducta engañosa, traicionera, dañina. Precisamente, lo que queremos expresar es que Sócrates rompe esa tendencia. Otro pasaje del Gorgias muestra a Calicles en protesta porque Sócrates se representa como un alumno -cosa que constituye una clara e ingeniosa ironía, puesto que Calicles siente sin duda que es al contrario, que el viejo Sócrates es el que todo el rato desempeña el papel de maestro. Sin embargo, en esta escena no se plantea el tema de la malicia o del subterfugio o de ser una evasión discursiva para sacer ventajas. Esto más bien se parece a una escena de Aristófanes en las Nubes donde aparece un

18 Aristóteles, (2000): Ética nicomaquea, Madrid, Gredos: 1127a 22 y 1127b 23.

19 Bloom, A. (1991): The Republic of Platon, New York: Basic Books. Brube, G. (2001): The Trial and Death of Socrates, Indianapolis: Hackett Publishing Co. Shorey, P. (1930): The Republic, London: Loeb Classical Library. 
anciano padre con la frase "este buen joven" para referirse a su hijo haragán. Aquí se reconoce el espíritu de la ironía pura como el agua, burla sin la menor disposición de engaño ${ }^{20}$.

Por todo lo anteriormente expuesto, entonces, quedaría planteado que la ironía como tal y más aún, por la ambigüedad de su uso, por la polifonía de enfoques deliberadamente ambiguos, por la dinámica de tropo en el lenguaje y especialmente, por haber sido adoptada en el "modo de filosofar socrático", pasó a convertirse en un mecanismo o elemento propio de la personalidad del hablante que está siempre bajo recelo, peligrosamente sospechoso de ser la palabra de un sofista o el efecto retórico, o de quien rompe la sinceridad del diálogo para beneficio propio o jactancia. La ironía socrática vive en esta situación crítica, tanto así que la mejor prueba son las escenas del renombrado juicio contra Sócrates, de quien no se tenía una opinión unánime sobre su persona: así fue visto como malicioso orador, un embaucador de los jóvenes, un transmisor de malas artes sofísticas, un irreligioso charlatán, un irónico de falsa sabiduría, etc, pero nadie lo vio como un ciudadano ocupado en cautelar el alma de la ciudad.

Desde la época sofística la "ironía” y el hombre irónico van a despertar intensas connotaciones negativas. Sin embargo, si vamos a la Roma de los siglos I a.C. y d.C., observamos un cambio asombroso: la palabra ha dejado de tener sus desagradables resonancias. Cicerón (106-34 a.C.) y más tarde Quintiliano $^{21}$ (35-95 d.C.) toman la palabra bajo otro rostro, manifestando ya sea el extremo de la urbanidad, de la fineza y del buen gusto. Unos dicen que hubo un cambio entre los sentidos propios de la palabra, una evolución en las zonas de sentido, como desde la periferia al centro. Sin mayores explicaciones histórico-filológicas del caso, no está claro que tipo de incidencias o bajo que factores pudo acontecer ese traslado semántico; faltan fuentes, referencias, huella en los documentos como tantas veces sucede.

Como observadores lejanos en el tiempo, sabemos que Sócrates caminó en las aguas de ese cambio, no específicamente por la corriente teórica del asunto sino creando más bien algo nuevo, un estilo de filosofar que hizo de la ironía un elemento pedagógico y psicológicamente estridente, un ruidoso ajetreo mental para quien tenía la ocasión de dialogar con el filósofo cuya academia era toda Atenas (y de paso decir que a vuelo imaginativo esa fue la primera Academia filosófica de la antigua Grecia).

20 Dover, K. (1968): p. 17.

21 Vlastos, G, op. cit: p. 67 y ss. 
Su ironía se quiere hacer un juego intelectual honrado, una ironía lúdica, no un engaño. Es en lo que se ha convertido, en un filósofo irónico, ironista, y que no lo oculta, más bien todos saben cuál es su juego y así lo respetan. Si bien se hizo de Sócrates un sofista más (caso de Aristófanes), o ya de un ilusionista del lenguaje dispuesto a hacer trampas como en las artes de la retórica y la oratoria, por otro lado, el uso y la intencionalidad misma de la ironía participó de otras orientaciones y sentidos en su discurso. La imagen de Sócrates como filósofo de la ironía metodológica y de la aporía existencial nos lleva a tomar en cuenta su extraño retrato de filósofo errante, y a suponer que lo que le ha llevado a ser condenado por sus jueces atenienses, no fueron tanto los delitos de la acusación como la propia ironía socrática jugando a rienda suelta y a su manera, llevando su estilo a un extremo, buscando darle al lenguaje retórico un soporte argumental, usando una metodología vital, existencial, siguiendo una vocación interrogativa sin fin, una ambigüedad de fronteras para hacer aparecer otros puntos de vista y que se oyera la voz de la razón misma más que imponiendo su propia yoidad. Aun si fuese cierto que nos dijera que no sabía nada, y que su papel de guía explorador y controlador en los diálogos fuese incidental, circunstancial y no siempre voluntario --precisamente así para no debatir o persuadir o convencer a sus oyentes y verse como un sofista más, etc. -- cuesta de situar donde está la sinceridad no irónica de una declaración así de directa. Aunque fuera cierto que él mismo decía a los demás que no se hicieran ilusiones al conversar con él, y que incluso, hiciera manifiesta confesión de humildad, eso mismo nos parece insólito, inimaginable, absolutamente intrigante, un rompe esquemas, una extravagante rasgadura de vestiduras, como se dice. Es como si un Académico de una prestigiosa universidad entrara a la sala en este momento y dijera en su primera afirmación que "Algunas veces, sin embargo, me parece lo contrario y vacilo sobre estas cosas, evidentemente porque no sé,"22 --palabras que aluden a un fragmento platónico. Esto causaría estupor y una sensación de incontrolable ironía entre ese orador y el auditorio que somos todos nosotros. Sin embargo, Sócrates era de tal naturaleza, de ese tipo de persona que se atrevía a ser así de natural o espontáneamente descarado o irónico, pero en donde la supremacía de su apostolado paideítico y psicagógico se elevan a una categoría filosófica de incontrovertible sentido y valor humanista. Al finalizar, imaginemos que la "filosa ironía socrática" es un axioma de la misma naturaleza del filosofar, que posee un parentesco con el asombro, la perplejidad y el éxtasis del pensar.

22 Platón, Hipias Menor, 372 d. 


\section{A modo de conclusión}

"Yo acuso", podría ser una de las primeras consignas esenciales del filosofar socrático, una impronta de qué acusación, preguntamos: de aquella que es vivir bajo una "comprensión fácil" de las cosas, del facilismo que hay en no cuestionar nada y menos a uno mismo. Pero junto a esa denuncia y voz de alerta para los habitantes de la polis y más aún de la propia humanidad, hay que reconocer que tal vez en maestros como Sócrates habita el extraño don mayeútico de la transformación, la de transformar la realidad vulgar y corriente de los hombres y llevarlos a salir del opio mental, de la mediocridad y la mentira a sí mismo. Quizá como profetas o viejos sabios de Oriente y Occidente, Sócrates ha demostrado que puede ayudar a transformar en hombres a los pequeños escombros de nuestra humanidad, siempre y cuando estemos dispuestos a nacer de nuevo de las palabras. El magisterio socrático solamente es para iniciar el camino, para dar los primeros pasos en nuestro pensar propio, pero luego estamos a nuestra suerte, como tiene que ser.

Fue Sócrates un filósofo de la ironía y del juego intelectual. Entonces, una doble vertiente tendría cabida: un horizonte de mismidad, el juego y mandato de la autorreflexión a fondo de uno mismo, y el respectivo desarrollo individual y a su vez, un horizonte de alteridad, el diálogo social con el otro, la paideia de una totalidad, la empatía encarnada en palabra humana. Un juego dramático, un juego humano y divino, un juego que no busca perder esa dimensión lúdica y de libertad: hay un juego intelectual que como juego irónico se abre a nuevas posibilidades y a la dinámica propia del juego que es también un puro fluir y estar en paz. Es el matiz propio de la palabra socrática que no pretende triunfar como una ciencia exacta del lenguaje ni como una ciencia de las duras o la matemática. No es una sequedad del espíritu o un dogma de sociedad. “iQué difícil es reconocer la propia ignorancia y qué liberador hacerlo!”, señala un terapeuta moderno, más aún cuando la educación vigente y de las elites va por una dirección opuesta al mandato socrático. El amén intelectual de hoy en día no es otro que el de "nunca muestres tu ignorancia: disimúlala, disfrázala, hazla inescrutable, enrédalos miente, pero jamás y por ninguna razón des tu brazo a torcer"23. Se entiende que Sócrates en nuestra sociedad hubiera sido igualmente acallado, silenciado, convertido intelectualmente en un homeless, pero a una más temprana edad.

La intención de este trabajo de aproximaciones es la invitación de que tengan una lectura ironista de la Apología buscando a ese otro Sócrates que 
despliega una filosofía aún no ortodoxa, y que por lo mismo, tiene todas las ventajas, todas las libertades de jugar con el lenguaje y de explorar la última habitación de nuestro yo.

Entonces, ¡oh, hermanos míos!, no repitamos el error ateniense, que no hayan copas de cicuta en las manos sino una enloquecida relectura de la Apología.

\section{BIBLIOGRAFÍA}

ARISTÓTELES (2000). Ética nicomaquea. Madrid: Gredos.

ARISTÓTELES (1951). El arte de la retórica. Mendoza: Universidad Nacional de Cuyo.

ARISTÓTELES (1999). Retórica. Madrid: Gredos

BLOOM, A. (1991). The Republic of Platon. NY: Basic Books.

BRUBE, G. (2001). The Trial and Death of Socrates. Indianapolis: Hackett Publishing Co.

CAVALLERO, P. (2005). "Trygoidía : la concepción trágica de Nubes de Aristófanes", XIII Jornadas de Estudios Clásicos "Grecia y Roma en España", UCA, Argentina, Biblioteca digital.

DEMÓSTENES (2011). Filípicas. Madrid: Gredos.

DOVER, K. L. (1972) Aristophanic Comedy. Londres: Batsford.

ERBSE, H. (1957). “Uber die ersten Wolken des Aristophanes”. En Newiger. Munchen: Beck.

HOMERO (1927). Odisea. Barcelona: Montaner y Simón.

JAEGER, W. (1945). Paideia. México: FCE.

KOPFF, E. C. (1990) “The date of Aristophanes' Clouds II”, AJP 11: 318-329, Texas: Johns Hopkins University Press.

NEWIGER, H. J. (1957). Metapher und Allegorie. Studien zu Aristophanes. Munchen: Beck.

PLATÓN (2007) Fedón, Barcelona: Gredos.

PLATÓN (2007) Hipias Menor, Barcelona: Gredos.

PLATÓN (1999). Leyes. Madrid: Gredos.

QUINTILIANO (1914). Instituciones Oratorias. Madrid: Imprenta de Perlado Paéz y Compañía.

REYES, A. (1941) La crítica en la edad ateniense, México: FCE.

RISO, W. (2007). El camino de los sabios. Barcelona: Planeta.

STOREY, I. CH. (1993): “The dates of Aristophanes' Clouds II and Eupolis' Baptai: a reply to E. C. Kopff', AJP 114. Texas: Johns Hopkins University Press.

SHOREY, P. (1930). The Republic. London: Loeb Classical Library.

VLASTOS, G. (1991). Socrates, Ironist and Moral Philosopher. NY: Cornell University Press. 